\title{
ARTIGOS
}

\section{ESTUDO DO COMPORTAMENTO DE CEPAS DE TRYPANOSOMA CRUZI APÓS PASSAGEM EM DIFERENTES ESPÉCIES DE TRIATOMÍNEOS}

\author{
Juracy B. Magalhães e Sonia G. Andrade
}

\begin{abstract}
Foi estudada a influência da passagem em diferentes espécies de triatomineos de cepas do T. cruzi biologicamente distintas, mantidas em camundongos. Cepas: Peruana (Tipo I), 12 SF (Tipo II), Colombiana (Tipo III). Triatomineos: Rhodnius prolixus, Panstrongylus megistus $e$ Triatoma infestans. Ninfas do $4^{\circ}$ estágio foram alimentadas em camundongos infectados com as respectivas cepas e obtidos os inóculos (10 formas metacíclinas) para infecção de camundongos de 8 a $10 \mathrm{~g}$. Grupos experimentais para cada cepa: 1 - Controles inoculados com formas sanguicolas; $\Pi$, Ill e $I V$ - inoculados com metaciclicos de $\mathrm{P}$. megistus, $\mathrm{T}$. infestans ou $R$. prolixus, respectivamente. Os perfis de parasitemia foram mantidos para cada cepa, com piques mais elevados nas infecções com metacíclicos do $\mathrm{P}$. megistus e do $\mathrm{R}$. prolixus, para a cepa Peruana, do P. megistus para a $12 \mathrm{SF}$ e do R. prolixus, para a Colombiana. $O$ histotropismo e o padrão de lesões foram mantidos para os três tipos de cepas. $O$ grau de virulência da cepa Peruana foi idêntico em todos os grupos e variou para as cepas 12 SF e Colombiana de acordo com a espécie de triatomíneo usada, com predominância de formas delgadas, nos inoculados com formas metaciclicas o que foi interpretado como uma fase adaptativa das formas metaciclicas ao hospedeiro vertebrado.
\end{abstract}

Palavras-chaves: Trypanosoma cruzi. Triatomíneos. Cepas do T. cruzi. Caracteres biológicos. Vetores.

Em trabalho anterior ${ }^{10}$ tivemos a oportunidade de verificar que a passagem das cepas Y e Peruana do $T$. cruzi em diferentes meios de multiplicação (culturas acelulares, passagem em triatomíneos) ou a manutenção em criopreservação, não alteravam o comportamento morfobiológico destas cepas, na infecção de camundongos, de acordo com critérios previamente estabelecidos ${ }^{1}$. No referido estudo, foi utilizado exclusivamente o $R$. prolixus para avaliar o efeito da passagem em triatomíneos sem que se tenham observado alterações do comportamento das mesmas. Também Garcia e cols ${ }^{6}$ verificaram que a passagem de uma cepa homogênea em triatomíneo não alterou os seus caracteres biológicos, bioquímicos e genéticos. Carvalheiro e Collares ${ }^{4}$,

\footnotetext{
Centro de Pesquisas Gonçalo Moniz/Fundação Oswaldo Cruz, Universidade Federal da Bahia, Salvador, BA.

Apoio financeiro do Conselho Nacional de Desenvolvimento Científico e Tecnológico (CNPq).

Endereço para correspondência: Dra. Sonia G. Andrade, R. Valdemar Falcão 121 Brotas, 41945 Salvador, BA.

Recebido para publicação em 14/06/91.
}

fazendo uma passagem da cepa $\mathrm{Y}$ em $T$. infestans verificaram a manutenção da virulência da cepa com altos níveis parasitêmicos e alta mortalidade, assinalando entretanto uma diminuição do reticuloptropismo, o que não foi por nós observado em relação ao $R$. prolixus. Outros autores, entretanto, comparando a infectividade de formas sanguícolas de diferentes cepas com a de formas metacíclicas dos triatomíneos encontraram maior infectividade nas primeiras, com maiores níveis parasitêmicos, bem como diferenças no viscerotropismo ${ }^{7114}$. Deste modo é de interesse verificar se as características de cepas de tipos biológicos padronizados (Tipos I, II e III) de acordo com Andrade', são mantidas após passagens em diferentes espécies de triatomíneos. Tendo em vista as diferenças geográficas de distribuição das espécies de triatomíneos na América Central e do $\mathrm{Sul}^{15}$ e no Brasil ${ }^{13}$ e levando em conta as diferenças de suscetibilidade de diferentes espécies de triatomíneos ${ }^{3816}$, o papel do inseto vetor deveria ser melhor avaliado quanto à sua influência na patogenicidade e virulência das cepas do $T$. cruzi . 
Magalhães JB, Andrade SG. Estudo do comportamento de cepas do Trypanosoma cruzi após passagem em diferentes espécies de triatomíneos. Revista da Sociedade Brasileira de Medicina Tropical 24:209-216, out-dez, 1991

\section{MATERIAL E MÉTODOS}

Camundongos suiços inoculados com $10^{5}$ formas sanguícolas do Trypanosoma cruzi dascepas Peruana (Tipo I), 12 SF (Tipo II) ou Colombiana (Tipo III) foram utilizados para a alimentação (xenodiagnóstico) das seguintes espécies de triatomíneos: Rhodnius prolixus, Panstrongylus megistus e Triatoma infestans. Foram utilizadas ninfas do $4^{\circ}$ estágio fornecidas pelo Laboratório de Parasitologia do Centro de Pesquisas Gonçalo Moniz. Os camundongos no $8^{\circ}$ dia de infecção pela cepa Peruana, no $12^{\circ}$ dia de infecção pela cepa 12 SF e no $18^{\circ}$ dia pela cepa Colombiana foram anestesiados e submetidos ao xenodiagnóstico em grupos individualizados para cada espécie de triatomíneo utilizada. As ninfas foram mantidas por 45 dias sem posterior alimentação. Para obtenção de inóculos provenientes de cada espécie de triatomíneo, o conteúdo intestinal dos insetos foi extraído, suspenso emPBS pH 7.2 e após três lavagens por centrifugação a $1.000 \mathrm{~g}$ com salina tamponada, feita contagem das formas metacíclicas em câmara Neubauer. Os inóculos foram padronizados em $10^{4}$ metacíclicos em 0,2 ml e inoculados em camundongos de 8 a $10 \mathrm{~g}$ por via intraperitoneal. Para cada cepa do $T$. cruzi, foram feitos 4 grupos experimentais: Grupo I camundongos controles, infectados com formas sanguícolas provenientes de camundongos; Grupo II - camundongos infectados com metacíclicos obtidos do P. megistus; Grupo III - camundongos infectados com metacíclicos provenientes do $T$. infestans; Grupo IV - camundongos inoculados com formas de $R$. prolixus.

Na Tabela 1 constam os números de animais de cada grupo. Como controles, camundongos suiços de 8 a $10 \mathrm{~g}$ foram inoculados com formas sanguícolas obtidas de camundongos, após três lavagens em salina tamponada e inóculos idênticos $\left(10^{4}\right)$, para as três cepas.

Os camundongos infectados, dos diversos grupos experimentais, foram acompanhados quanto à evolução de parasitemia, à morfologia dos parasitos no sangue periférico, aos índices de mortalidade e às lesões histopatológicas no curso da infecção. A parasitemia foi avaliada em 5 animais de cada grupo, no sangue periférico, entre lâmina e lamínula em 50 campos microscópicos de X400 e expressa pela média aritmética do número de parasitos encontrado. $O$ estudo morfológico foi feito em esfregaços de sangue periférico, corados pelo método de Giemsa, do $7^{\circ}$ ao $14^{\circ}$ dias pós infecção através contagem percentual de formas largas e delgadas. A mortalidade foi avaliada pela percentagem de animais que morreram durante a infeç̧ão excluídos os sacrificados. Os dados de mortalidade nos diversos grupos constam da Tabela 1.

O estudo histopatológico foi feito em camundongos sacrificados no $7^{\circ}, 10^{\circ}, 12^{\circ}, 14^{\circ} \mathrm{e}$ $17^{\circ}$ dias pós infecção com a cepa Peruana e no $7^{\circ}$, $12^{\circ}, 15^{\circ}, 20^{\circ}, 25^{\circ}$ e $30^{\circ}$ com as cepas 12 SF ou Colombiana. Os animais sacrificados após anestesia pelo éter, foram submetidos a autópsias completas e fragmentos dos diversos órgãos fixados em formol a $10 \%$.

\section{RESULTADOS}

\section{Camundongos infectados com a cepa Peruana.}

a. Evolução da parasitemia. Na Figura 1 estão expressos os níveis de parasitemia nos diversos grupos de infecção pela cepa Peruana. Em todos os grupos observou-se acentuada e precoce elevação da parasitemia, com piques elevados do $8^{\circ}$ ao $14^{\circ}$ dia, observando-se os níveis mais elevados nos infectados com formas do $P$. megistus e do $R$. prolixus.

b. Os indices de mortalidade foram de $100 \%$ do

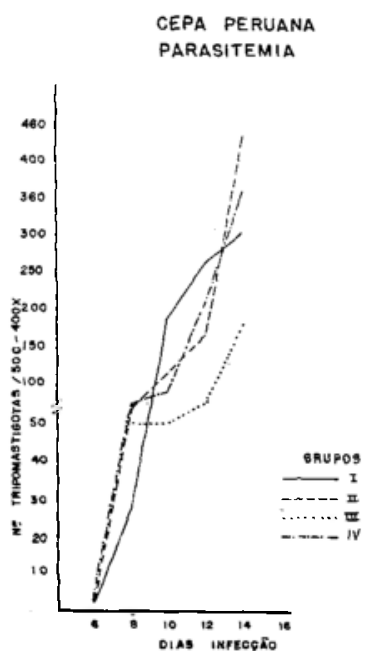

Figura 1 - Mivets de parasitemia em camundongos infectados com a cepa Peruana: Grupo I - inóculo proveniente de camundongos; Grupo II - inóculo de P. megistus; Grupo III - inóculo de T. infestans; Grupo IV-inóculo de R. prolixus. 
Magalhães JB, Andrade SG. Estudo do comportamento de cepas do Trypanosoma cruzi após passagem em diferentes espécies de triatomíneos. Revista da Sociedade Brasileira de Medicina Tropical 24:209-216, out-dez, 1991

$14^{\circ}$ ao $17^{\circ}$ dia pós infecção, para todos os grupos experimentais (Tabela 1).

c. O estudo morfológico (Tabela 2) mostrou predominância de formas delgadas até o $14^{\circ}$ dia nos animais infectados com formas sanguícolas e com inóculo proveniente do $R$. prolixus. Nos inoculados com formas derivadas do $P$. megistus e do $T$. infestans as formas delgadas predominaram até o $10^{\circ}$ dia e no $14^{\circ}$ predominavam as formas largas. d. Estudo histopatológico - a infecção com

Tabela 1 - Dados Gerais - Infecção de camundongos com diferentes cepas do T. cruzi (formas sanguicolas e metacíclicas)

\begin{tabular}{|c|c|c|c|c|c|c|}
\hline \multirow{2}{*}{ Grupos* } & \multicolumn{2}{|c|}{ Peruana } & \multicolumn{2}{|c|}{$12 \mathrm{SF}$} & \multicolumn{2}{|c|}{ Colombiana } \\
\hline & $\begin{array}{c}\mathrm{N}^{\circ} \\
\text { Animais }\end{array}$ & $\begin{array}{c}\text { Mortalidade } \\
\%\end{array}$ & $\begin{array}{c}\mathbf{N}^{\circ} \\
\text { Animais }\end{array}$ & $\begin{array}{c}\text { Mortalidade } \\
\%\end{array}$ & $\begin{array}{c}\mathrm{N}^{\circ} \\
\text { Animais }\end{array}$ & $\begin{array}{c}\text { Mortalidade } \\
\%\end{array}$ \\
\hline I. Controles & 20 & 100 & 20 & 69 & 20 & 7 \\
\hline II. P. megistus & 8 & 100 & 20 & 62 & 8 & 45 \\
\hline III. T. infestans & 11 & 100 & 27 & 90 & 11 & 92 \\
\hline IV. R. prolixus & 8 & 100 & 24 & 33,3 & 8 & 100 \\
\hline
\end{tabular}

* Origem do inóculo: $10^{4}$ formas sanguícolas (I) e $10^{4}$ metacíclicos (II, III, IV)

Tabela 2 - Cepa Peruana do T. cruzi - Estudo morfológico. Percentagem de formas tripomastigotas largas e delgadas no sangue periférico.

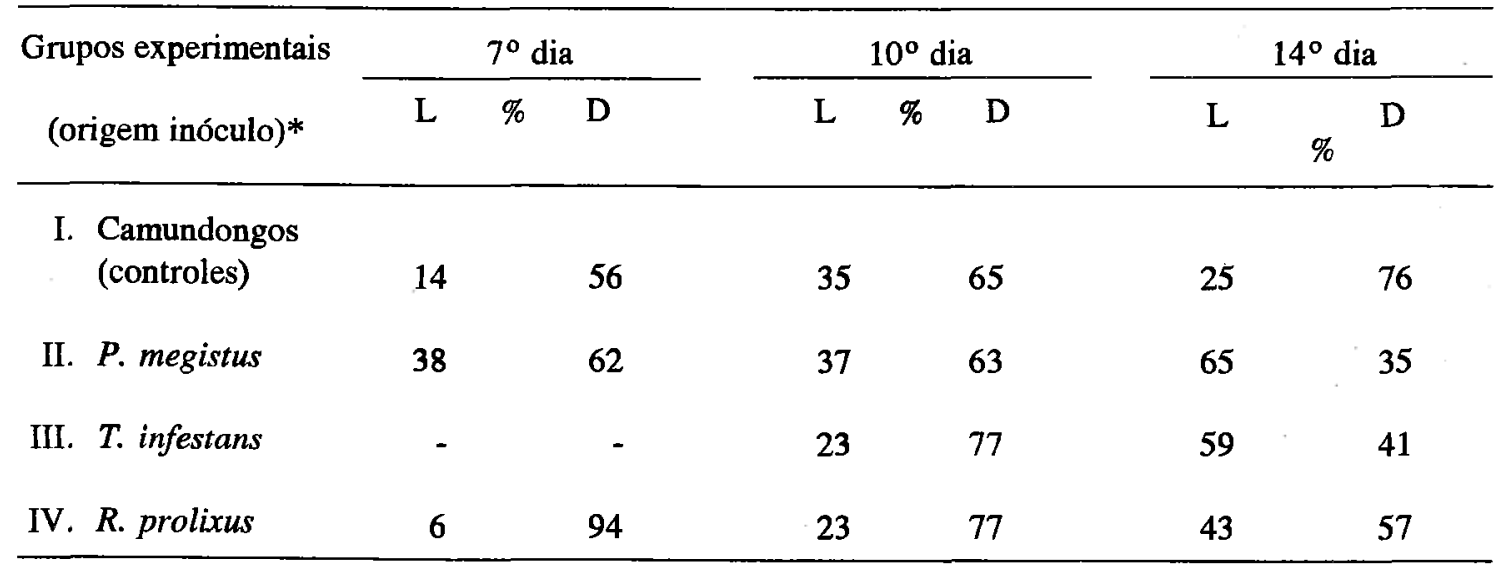

* I = Formas sanguícolas; II, III, IV = formas metacíclicas.

- $n^{\circ}$ insuficiente para estudo; $L=$ largas, $D=$ delgadas 
Magalhães JB, Andrade SG. Estudo do comportamento de cepas do Trypanosoma cruzi após passagem em diferentes espécies de triatomineos. Revista da Sociedade Brasileira de Medicina Tropical 24:209-216, out-dez, 1991

formas sanguícolas provenientes de camundongos determinou moderado macrofagotropismo a partir do $7^{\circ}$ dia de infecção e discreto parasitismo de músculo esquelético e de miocárdio no $10^{\circ}$ e $12^{\circ}$ dias. Aos 17 dias observou-se acentuado parasitismo e intenso processo inflamatório em miocárdio e músculo esquelético. Nos camundongos infectados com inóculos provenientes das três espécies de triatomíneos, o parasitismo de macrófagos só foi visto a partir do $13^{\circ}$ dia de infecção, em baixa intensidade. Aos 13 dias observou-se discreto parasistismo e discreto processo inflamatório em miocárdio e músculo esquelético que se intensificou entre $15^{\circ}$ e $17^{\circ}$ dias pós infecção.

\section{Camundongos infectados com a cepa 12 SF.}

a. Evolução da parasitemia (Figura 2). No grupo controle inoculado com formas sanguícolas, observou-se rápida elevação da parasitemia a partir do $12^{\circ}$ dia de infecção, ocorrendo piques elevados entre o $12^{\circ}$ e o $20^{\circ}$ dias. Nos grupos inoculados com formas metacíclicas de triatomíneos observaram-se piques parasitêmicos entre o $18^{\circ} \mathrm{e}$ $24^{\circ}$ dias. O nivel mais elevado foi detectado nos infectados com inóculo do $P$. megistus.

\section{CEPA 12 SF}

\section{PARASITEMIA}

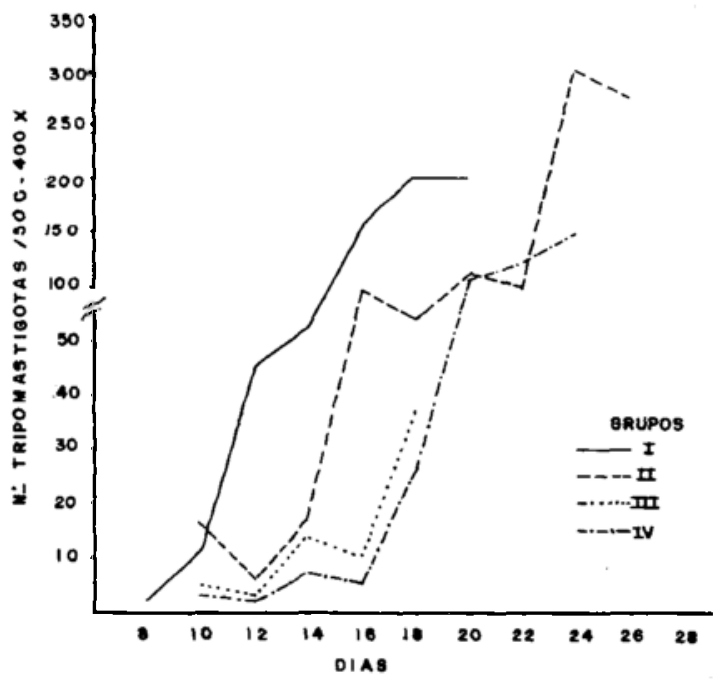

Figura 2 - Niveis de parasitemia em camundongos infectados com a cepa 12 SF: Grupo I - inóculo proveniente de camundongos; Grupo II - inóculo de P. megistus; Grupo III - inóculo de T. infestans; Grupo IV - inóculo de R. prolixus. b. Os indices de mortalidade até o $20^{\circ}$ dia de infecção estão expressos na Tabela 1, observandose o índice mais elevado nos infectados com a cepa proveniente do $T$. infestans $(90 \%)$ e o menos elevado com o inóculo do $R$.prolixus $(33,3 \%)$.

c. Estudo morfológico (Tabela 3) mostrou predominância de formas largas nos camundongos inoculados com formas sanguícolas e de formas delgadas nos inoculados com formas provenientes das três espécies de triatomíneos.

d. Estudo histopatológico. Nos camundongos controles, infectados com formas sanguícolas da cepa 12 SF, observou-se aos 13 dias, moderado parasitismo de miocárdio, que se intensificou no $16^{\circ}$ dia, tornando-se muito intenso no $24^{\circ}$ dia de infecção, acompanhado do infiltrado inflamatório mononuclear de moderada intensidade. Também em músculo esquelético o parasitismo variou de discreto a moderado no $16^{\circ}$ e $24^{\circ}$ dias com moderada inflamação. Aos 16 dias as lesões determinadas pelo inóculo proveniente do $\boldsymbol{P}$. megistus foram semelhantes às dos controles inoculados com formas sanguícolas, enquanto com os inóculos do $T$. infestans e do $R$. prolixus, o parasitismo era menor. Aos 24 dias de infecção observou-se parasitismo intenso de miocárdio, acompanhado de acentuado processo inflamatório em todos os grupos inoculados com formas provenientes de triatomíneos idênticos aos determinados por formas sanguícolas.

\section{Camundongos infectados com cepa Colombiana.}

a. Evolução da parasitemia. (Figura 3). Tanto nos camundongos infectados com formas sanguícolas como nos infectados com formas metacíclicas das três espécies de triatomíneos, os piques de parasitemia ocorreram entre $024^{\circ}$ e o $30^{\circ}$ dias de infecção, com uma evolução mais precoce nos inoculados com formas sanguícolas e pique máximo nos infectados com formas do $R$. prolixus.

b. Os indices de mortalidade (Tabela 1) foram variáveis para os 4 grupos e mais elevados nos inoculados com formas do $T$. infestans (92\%) e do $R$. prolixus (100\%) até o $26^{\circ}$ dia de infecção.

c. Ao estudo morfológico houve predominância de formas largas no grupo controle e nos inoculados com formas de $P$. megistus e predominância de formas delgadas nos inoculados com formas 
Magalhães JB, Andrade SG. Estudo do comportamento de cepas do Trypanosoma cruzi após passagem em diferentes espécies de triatomíneos. Revista da Sociedade Brasileira de Medicina Tropical 24:209-216, out-dez, 1991

Tabela 3 - Cepas 12 SF e Colombiana do T. cruzi - Estudo morfológico. Percentagem de formas tripomastigotas largas e delgadas do $\mathrm{T}$. cruzi no sangue periférico.

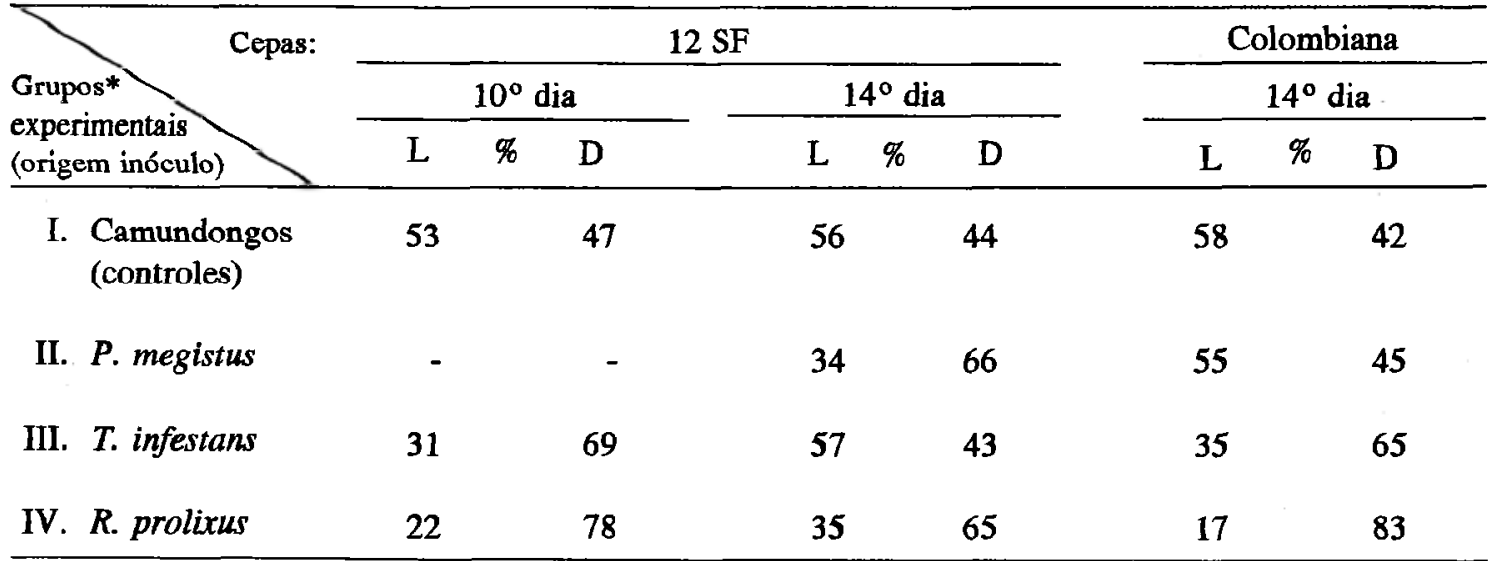

* I = Formas sanguícolas; II, III, IV = formas metacíclicas; L = largas; D = delgadas - $\mathrm{n}^{0}$ insuficiente para estudo.

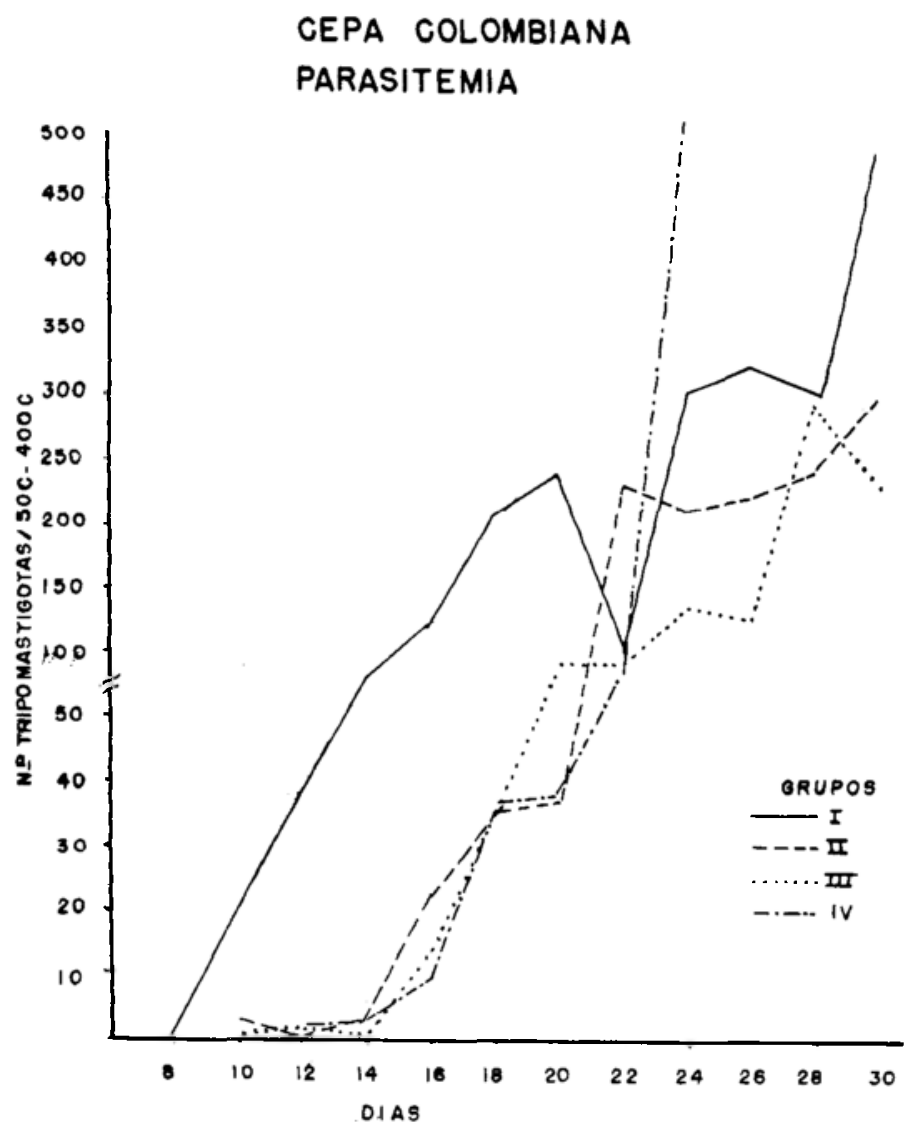

Figura 3 - Niveis de parasitemia em camundongos infectados com a cepa Colombiana: Grupo I - inbculo proveniente de camundongos; Grupo II - inóculo de P. megistus; Grupo III - inóculo de T. infestans; Grupo IV - inóculo de R. prolixus. 
Magalhães JB, Andrade SG. Estudo do comportamento de cepas do Trypanosoma cruzi após passagem em diferentes espécies de triatomíneos. Revista da Sociedade Brasileira de Medicina Tropical 24:209-216, out-dez, 1991

provenientes do T. infestans eR. prolixus (Tabela3).

d. Estudo histopatológico. Nos controles infectados com formas sanguícolas da cepa Colombiana, observou-se presença de parasitos e moderado processo inflamatório em miocárdio e músculo esquelético a partir do $15^{\circ}$ dia de infecção, o que se acentuou no $20^{\circ}, 25^{\circ}$ e $30^{\circ}$ dias. O infiltrado inflamatório nesta fase era idêntico em miocárdio e músculo esquelético, variando de moderado a intenso e o parasitismo era de moderada intensidade. Aos 35 dias, observou-se intensa miocardite e miosite, com escassos parasitos. As lesões observadas com o inóculo obtido do $T$. infestans foram idênticas às observadas nos controles inoculados com formas sanguícolas. Na infecção com metacíclicos provenientes do $P$. megistus e do $\boldsymbol{R}$. prolixus as lesōes e o parasitismo foram mais intensos.

\section{DISCUSSÃO}

A proposta do presente trabalho foi de verificar se cepas do T. cruzi mantidas em laboratório por passagens sucessivas em camundongos teriam modificado o seu comportamento biológico após a passagem em diferentes espécies de triatomíneos. Recentemente, Perlowagora-Szumlewicz e cols ${ }^{12}$ mostraram nítidas diferenças na infectividade de cepas do $T$. cruzi para diferentes espécies de triatomíneos, na dependência do tipo biológico e isoenzimático da cepa. Neste particular chamam a atenção estes autores, para alta infectividade da cepa São Felipe (Tipo II e zimodema 2) e a baixa infectividade da cepa Colombiana (Tipo III e zimodema 1). Deste modo, parece interessante investigar se a passagem em triatomíneos das cepas com características biológicas e isoenzimáticas definidas ${ }^{3}$ poderia determinar alteraçôes na sua evolução, virulência e patogenicidade para o animal experimental, especificamente o camundongo. Os resultados obtidos no presente trabalho demonstraram que as diversas cepas mantiveram os caracteres biológicos, avaliados de acordo com parâmetros já bem estabelecido', mantendo os perfis de parasitemia, embora com um retardona evolução, nas cepas $12 \mathrm{SF}$ e Colombiana provenientes de triatomíneos, mantendo também o mesmo tropismo tissular e a mesma patogenicidade. O retardo na evolução da parasitemia correspondeu a um menor grau de parasitismo nas fases iniciais de infecção, quando comparados aos controles infectados com formas sanguícolas. Foi observada entretanto, na evolução posterior, nítida elevação dos níveis parasitêmicos das diversas cepas provenientes de triatomíneos, por vezes atingindo níveis mais elevados do que os observados nos controles. Do mesmo modo, as lesões tissulares, que foram mais tardias, atingiram a mesma intensidade na fase final de observação na maioria dos grupos, podendo mesmo ser mais intensas, como foi observado com a cepa Colombiana proveniente do $P$. megistus e do $R$. prolixus. Vale assinalar que o comportamento de cada espécie de triatomíneo não foi uniforme em relação aos três tipos de cepas no que diz respeito à virulência do inóculo obtido. Um exemplo disto é o R. prolixus, cujo inóculo da cepa Colombiana determinou o mais alto índice de mortalidade $(100 \%)$ enquanto com a cepa $12 \mathrm{SF}$, o inóculo proveniente do $R$. prolixus determinou o menor índice de mortalidade para esta cepa $(33,3 \%)$. Comparando a virulência das diferentes cepas do $T$. cruzi após passagem nas três espécies de triatomíneos verificouse que a cepa $12 \mathrm{SF}$ é mais virulenta quando proveniente do $P$. megistus e do $T$. infestans e a cepa Colombiana, do $P$. megistus e do $R$. prolixus. A cepa Peruana mostrou virulência atenuada em todos os grupos, quando comparada com os padrões descritos anteriormente ${ }^{12}$. Isto foi atribuído ao baixo inóculo pois, como foi demonstrado em trabalho anterior ${ }^{10}$, com as cepas de Tipo I, houve nítida influência do inóculo quando se utilizaram inóculos de $10^{4}$ ou $5 \times 10^{4}$. A cepa Peruana manteve a predominância de formas delgadas em todos os grupos. Entretanto observou-se que após a passagem em triatomíneos, passaram a predominar as formas delgadas na infecção pela cepa $12 \mathrm{SF}$ o mesmo acontecendo com a cepa Colombiana proveniente do $R$. prolixus e do $T$. infestans. $O$ aparecimento de formas delgadas nas cepas passadas em triatomíneos, juntamente com retardo verificando na evolução da parasitemia e do parasitismo tissular poderiam representar uma fase adaptativa das formas provenientes do vetor no hospedeiro vertebrado.

\section{SUMMARY}

To study the influence of the intermediate host 
Magalhães JB, Andrade SG. Estudo do comportamento de cepas do Trypanosoma cruzi após passagem em diferentes espécies de triatomíneos. Revista da Sociedade Brasileira de Medicina Tropical 24:209-216, out-dez, 1991

stage on the course of mouse infection, Trypanosoma cruzi belonging to the Peruvian (Type I), 12 SF (Type II) and Colombian (Type III) strains were passaged through either Rhodnius prolixus, Panstrongylus megistus or Triatoma infestans. T. cruzi metacyclic forms (dose $10^{4}$ ) from the different strains were obtained from each bug and inoculated into $8-10 \mathrm{gm}$ mice. Comparison was made in mice inoculated with blood forms. Parasitaemia curves were plotted in the peripheral blood for each strain, reaching more elevated peaks with Peruvian strain parasites from $\mathrm{P}$. megistus and $\mathrm{R}$. prolixus, 12 SF strain from $\mathrm{P}$. megistus and Colombian strain from $\mathrm{R}$. prolixus. Tissue tropism and histopathological patterns were those usually seen in mice infected with each respective strain type. Peruvian virulence was the same for all groups. Slender forms predominate among mice inoculated with metacyclic forms of Colombian and 12 SF strains, probably an adaptative parasite change related to the intermediate host.

Key-words: Trypanosoma cruzi. Triatominae. T. cruzi strains. Biological characters. Vectors.

\section{AGRADECIMENTOS}

Ao Dr. Italo Sherlock Chefe do Laboratório de Parasitologia do Centro de Pesquisas Gonçalo Moniz/FIOCRUZ/UFBA, pelo constante apoio no fornecimento das espécies de triatomíneos utilizadas no presente trabalho.

\section{REFERÊNCIAS BIBLIOGRÁFICAS}

1. Andrade SG. Caracterização de cepas do Trypanosoma cruzi isoladas no Recôncavo Baiano. Revista de Patologia Tropical 3:65-121, 1974.

2. Andrade SG, Carvalho ML, Figueira RM. Caracterização morfo-biológica e histopatológica de diferentes cepas do Trypanosoma cruzi. Gazeta Médica da Bahia 70:32-42, 1970.

3. Andrade V, Brodskyn C, Andrade SG. Correlation between isoenzyme patterns and biological behaviour of different strains of Trypanosoma cruzi. Transaction of Royal Society of Tropical Medicine and Hygiene 77:796-799, 1983.

4. Carvalheiro JR, Collares EF. Estudos sobre o comportamento em camundongos de uma amostra altamente virulenta de Trypanosoma cruzi (amostra Y), após passagem em triatomíneos, ratos e culturas. Revista Brasileira de Biologia 25:169-175, 1965.

5. Cerisola JA, Rohwedder RW, Del Prado CE. Rendimento del xenodiagnostico en la infeccion chagásica cronica humana utilizando ninfas de diferentes especies de triatomíneos. Boletin Chileno de Parasitologia 26:57-58, 1971.

6. Garcia ES, Vieira E, Gonçalves A, Morel CM, Colli MAW. A strain of Trypanosoma cruzi and its biochemical characterization after passage through different invertebrate hosts. Annals of Tropical Medicine and Parasitology 80:361-363, 1986.

7. Lammel EL, Muller LA, Isola ELD, Gonzalez Cappa SM. Effect of vector on infectivity of Trypanosoma cruzi. Acta Tropica 42:149-155, 1985.
8. Little JW, Tay J, Biagi F. A study on the susceptibility of triatomid bugs to some Mexican strains of Trypanosoma cruzi. Journal of Medicine and Entomology 3:252-255, 1966.

9. Lucena DT. Ecologia dos triatomíneos do Brasil. Revista Brasileira de Malariologia e Doenças Tropicais 11:577-635, 1959.

10. Magalhães JB, Pontes $A L$, Andrade SG. Comportamento das cepas $Y$ e Peruana do Trypanosoma cruzi no camundongo, após passagem em diferentes meios. Memórias do Instituto Oswaldo Cruz 80:41-50, 1985.

11. Neal RA, Mc Hardy M. Comparison of infectivity of Trypanosoma cruzi blood stream trypomastigotes and metacyclic trypomastigote from Rhodnius prolixus. Acta Tropica 34:79-85, 1977.

12. Perlowagora-Szumlewicz A, Muller CA, Moreira CJC. Studies in search of suitable experimental insect model for xenodiagnosis of hosts with Chagas'disease. 4 - The reflection of parasite stock in the responsiveness of different vector species to chronic infection with different Trypanosoma cruzi stocks. Revista de Saúde Pública de São Paulo 24:165-177, 1990.

13. Sherlock IA, Serafim EM. Fauna triatominae do Estado da Bahia, Brasil. VI - prevalência geográfica da infecção dos triatomíneos por T. cruzi. Revista da Sociedade Brasileira de Medicina Tropical 8:129$142,1974$.

14. Tay J, Schetino PMS, Ontiveros D. El comportamiento en el ratón blanco de una cepa de 
Magalhães JB, Andrade SG. Estudo do comportamento de cepas do Trypanosoma cruzi após passagem em diferentes espécies de triatomíneos. Revista da Sociedade Brasileira de Medicina Tropical 24:209-216, out-dez, 1991

Trypanosoma cruzi mediante pases sucesivos en diferentes especies de triatomas. Revista Latino Americana de Microbiologia e Parasitologia 11:7989, 1969.

15. Zeledon $R$. Los vectores de la enfermedad de Chagas en America. In: Anais do Simpósio
Internacional de Doença de Chagas, Buenvs Aires p.327-345, 1972.

16. Zeledon R,Vieto E. Susceptibilidad de varias especies de triatomineos a una cepa costarricense de Schizotrypanum cruzi, Chagas. 1901. Revista de Biologia Tropical 5:195-199, 1957. 